\title{
Unilateral cataplexy associated with systemic lupus erythematosus
}

\author{
R. G. LASCELLES, P. D. MOHR, AND I. PEART \\ From the University Department of Neurology, Manchester Royal Infirmary, Manchester
}

SYNOPSIS A patient with systemic lupus erythematosus (SLE) developed attacks of unilateral cataplexy precipitated by laughter. Unilateral cataplexy has not been described previously in detail and its association with SLE is unique. The clinical details, investigations, and diagnostic criteria are discussed and a causal relationship between cataplexy and SLE is suggested.

Partial forms of cataplexy are rare and usually take the form of transient weakness of the jaw, knees, or other midline structures, occurring in patients with the classical tetrad of naicolepsy-narcolepsy, cataplexy, sleep paralysis and hypnogogic hallucinations; they represent mild forms of the more classical generalised attack (Devic et al., 1967; Mackenzie, 1967; Guilleminault et al., 1974). Wilson (1928) has described cataplexy affecting only an arm or a leg in sportsmen making a difficult stroke at tennis or kicking a ball, but attacks affecting one half of the body including the face have only been mentioned briefly in one report (Yoss and Daly, 1957).

The cause of narcolepsy and cataplexy is unknown but it is thought to be due to a primary abnormality in the pontomesencephalic reticular formation (Guilleminault et al., 1974). A few isolated examples of syphilis, encephalitis, multiple sclerosis, and benign intracranial hypertension have been described in patients with narcolepsy (MacKenzie, 1967; Wilson, 1928; Zarcone, 1973) but not cataplexy, and the classical narcoleptic tetrad has not been linked with any underlying structural abnormality. Although neurological manifestations of systemic lupus erythematosus (SLE) are well recognised (Bennett et al., 1972; Decker et al., 1975), no association between cataplexy and SLE has been reported. We have recently encountered a unique patient with SLE who developed attacks of unilateral cataplexy and the details are reported below.

(Accepted 9 June 1976.)

\section{REPORT OF A CASE}

A woman aged 41 years was admitted to the neurology unit in November 1974. She had first attended the dermatology clinic in 1969 with general malaise, aches and pains in her joints, and a rash which was aggravated by sunlight. Examination at that time revealed a mild polyarthralgia without joint swelling and a macular rash on the face, trunk, and arms. The only abnormal laboratory test at that time was a positive antinuclear factor (ANF) test and a provisional diagnosis of SLE was made. She was treated with systemic corticosteroids and her signs and symptoms subsided. The corticosteroids were discontinued in November 1972 and reinvestigation revealed positive tests for lupus erythmatosus (LE) cells.

She remained well until December 1973 when she started to have attacks of weakness of the right half of the body and face brought on by laughter. The attacks were only triggered by loud or irresistible laughter which she described as a 'belly laugh', often associated with one particular comedian. The weakness took the form of complete loss of use of the right arm and leg with drooping of the right side of the face. There were no associated sensory symptoms, no convulsive or abnormal movements, no loss of consciousness, and no incontinence. The attacks lasted for 0.5-2 minutes after which she would suddenly return to normal without any after-effects. These episodes occurred at least four or five times a month. Direct questioning revealed that over the previous two years she had had attacks of falling asleep in unusual situations and one episode of sleep paralysis. She had had a severe recurrence of her rash and arthralgia since the attacks started. 


\section{EXAMINATION}

A 'butterfly' rash was noted on the face and there was superficial oedema and keratin plugging of the skin pores. A more patchy macular rash was seen on the trunk, neck, and arms. In between attacks examination of the nervous system was normal. At this time there was no polyarthritis and examination of the other systems was also normal.

\section{DESCRIPTION OF ATTACKS}

While in hospital the patient had 22 attacks of rightsided weakness, many of which were witnessed and photographed by the medical staff (Figs. 1 and 2). A description of one attack was recorded as follows: 'Mrs X was sitting upright in bed. One of the patients said something extremely funny and Mrs $\mathrm{X}$ began to roar with laughter, she fell back against the pillow, the right side of the face drooped, her right arm and hand became limp and she dropped a cigarette onto the bedcovers. The weakness lasted for approximately 15 seconds.' Some attacks lasted up to three minutes and during these episodes examination revealed a flaccid paralysis of the right side with absent tendon reflexes and an extensor right plantar response. Sensory testing was normal. The patient had difficulty in talking during the attacks but there was no loss of consciousness.

\section{INVESTIGATIONS}

The following results were abnormal: Westergren erythrocyte sedimentation rate (ESR) $50-73 \mathrm{~mm}$ in first hour; serum globulin $41 \mathrm{~g} / \mathrm{l}$, serum albumin 37 $\mathrm{g} / \mathrm{l}$. Electrophoresis of the plasma proteins showed a diffuse increase in the gamma globulin fraction; immunoglobulin assay showed increased $\operatorname{IgM}(1.8 \mathrm{~g} / \mathrm{l})$ and IgG $(2.7 \mathrm{~g} / \mathrm{l})$ levels. Tests for ANF and LE cells

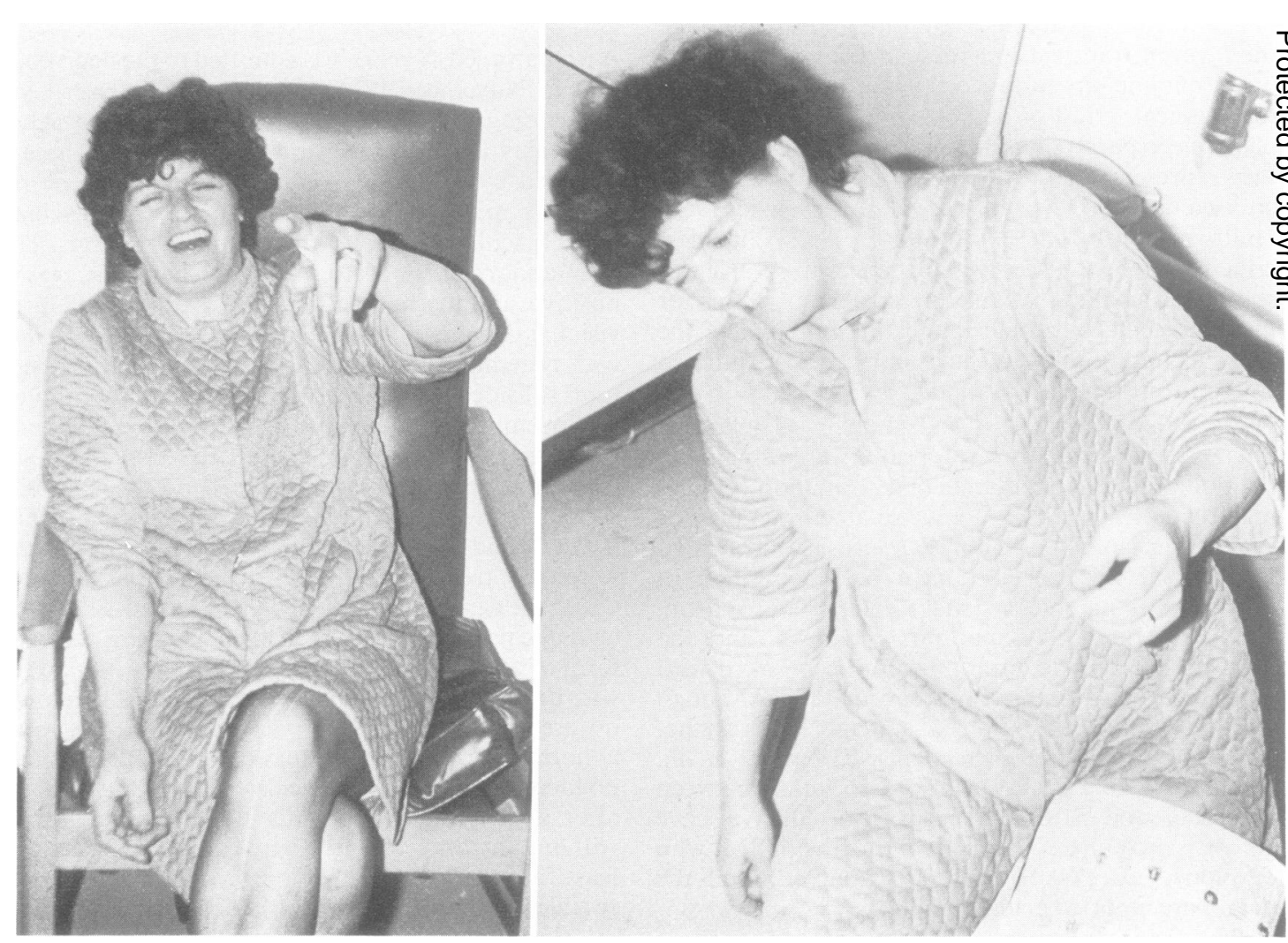

FIG. 1 (left) Patient in the early stage of an attack of unilateral cataplexy. She is being asked to hold both arms out; the right arm is limp and she is falling over to the right side. FIG. 2 (right) Patient in a more advanced stage of an attack of unilateral cataplexy. She is being asked to hold her arms out. Her right side is weak and limp. 
were positive on two occasions. Anti-DNA antibodies were at the upper limit of normal $(27 \mathrm{u} / \mathrm{ml}$ Electroencephalography showed a diffuse excess of slow wave activity in the theta range. No rapid eye movement activity was noted. The cerebrospinal fluid protein was $0.32 \mathrm{~g} / \mathrm{l}$ with an $\mathrm{IgG}$ of $0.062 \mathrm{~g} / \mathrm{l}(19.4 \%$ of total protein).

A number of other investigations revealed normal results including radiographs of the skull and chest, bilateral carotid angiograms, pneumoencephalogram, technetium brain scan, computerised axial tomography (EMI scan), electrocardiogram, full blood count, serum urea, electrolytes, alkaline phosphatase and calcium, thyroid function tests, serological tests for syphilis, tests for rheumatoid factor, creatinine clearance, 24 hour urinary protein, and tirine microscopy.

\section{TREATMENT AND PROGRESS}

The patient was started on prednisolone $45 \mathrm{mg}$ daily in December 1974. From that time until May 1975 she had only two attacks of weakness. The rash and arthralgia improved and the ESR fell to normal. In June 1975 she stopped the prednisolone and the attacks returned. The rash was exacerbated by exposure to sun-ray lamp and she complained of joint pain. In July 1975 she was seen in the department of rheumatology with tendonitis of the long head of biceps and synovitis of the ankle joint. The ESR rose to $43 \mathrm{~mm}$ per hour. She continued to have attacks of weakness and two attempts were made to treat her with clomipramine which she was unable to tolerate because of lethargy and epistaxis. In January 1976 the arthralgia was so severe that she was restarted on prednisolone $15 \mathrm{mg}$ daily and again improved.

\section{DISCUSSION}

This patient presents a unique problem of attacks of unilateral cataplexy associated with SLE. Before suggesting a causal relationship it is important to ensure that the diagnostic c:iteria for both conditions are strictly fulfilled.

The diagnostic features of cataplexy are well recognised (Guilleminault et al., 1974; Parkes and Marsden, 1974). The weakness is characterised by a sudden loss of muscle tone triggered by an emotional factor which is usually uncontrollable laughter, described by Gélineau (1880) as the riait aux éclats. During the attacks the tendon reflexes and $\mathrm{H}$-reflex are abolished and the plantar responses are extensor (Wilson, 1928). Cataplexy usually affects the whole body but this is not essential for the diagnosis and partial forms affecting the jaw, knees (Devic et al., 1967), or just one limb (Wilson, 1928) are recognised, although these patients also have the generalised attacks. Yoss and Daly (1957) have described a patient in whom the attacks affected only the right side of the body. They considered this unique but gave no further details. The absence of convulsive movements or loss of consciousness differentiate cataplexy from gelastic epilepsy (Chen and Forster, 1973), but only close observation would differentiate unilateral cataplexy from the extremely rare condition of focal gelastic epilepsy described by Nattrass (1931).

The diagnostic criteria for SLE are strict and a patient must have at least four of the features in the check-list laid down by the American Rheumatism Association (Decker et al., 1975). A provisional diagnosis of SLE was made on the basis of three features: positive LE cells, typical facial rash, and photosensitivity. The neurological involvement could not be considered a fourth feature because of its unusual nature. A firm diagnosis of SLE was established when the patient developed an inflammatory arthritis. The positive ANF test, elevated serum globulin, immunoglobulins, and ESR together with arthralgia are additional minor features which support the diagnosis.

As far as we know there are no reports of cataplexy associated with SLE, although neurological involvement in SLE is well recognised; psychosis, fits, chorea, neuropathy, hemiplegia, brain-stem and cord syndromes have all been reported (Bennett et al., 1972; Lusins and Szilagyi, 1975). The pathological changes are those of a patchy and focal vasculitis with focal encephalomalacia or areas of demyelination (Penn and Rowan, 1968) and immune complexes have been reported in the choroid plexus (Atkins et al., 1972). It is reasonable to postulate that a focal vasculitis in the pontomesencephalic reticular formation could be responsible for the clinical picture in the present patient; this would be compatible with the investigations including the normal findings at neuroradiology.

Our patient was unable to tolerate clomipramine, the treatment of choice in cataplexy (Shapiro, 1975) but the decrease in frequency of her attacks while she was taking corticosteroids further suggests a causal relationship between her unilateral cataplexy and SLE. During the six months period of treatment she had only two attacks compared with the 22 observed in the previous six weeks. This view was strengthened by the fact that her attacks increased when the corticosteroids were discontinued. These fluctuations in the frequency of her attacks parallelled the improvement and deterioration in her SLE.

We would like to thank Dr P. J. L. Holt for his help in establishing the diagnosis of SLE and for doing the anti-DNA antibody assay. 


\section{REFERENCES}

Atkins, C. J., Kondon, J. J., Quismorio, F. P., and Friou, G. J. (1972). The choroid plexus in systemic lupus erythematosus. Annals of Internal Medicine, 76, 65-72.

Bennett, R., Hughes, G. R. V., Bywater, E. G. L., and Holt, P. J. L. (1972). Neuropsychiatric problems in systemic lupus erythematosus. British Medical Journal, 4, 342-345.

Chen, R. C., and Forster, F. M. (1973). Cursive epilepsy and gelastic epilepsy. Neurology (Minneap.), 23, 10191029.

Decker, J. L., Steinberg, A. D., Gershwin, M. E., Seaman, W. E., Klippel, J. H., Plotz, P. H., and Paget, S. A. (1975). Systemic lupus erythematosus, contrasts and comparisons. Annals of Internal Medicine, 82, 391-404.

Devic, M., Aimard, P., Michel, F., and Masquin, M. O. (1967). Étude clinique des narcolepsies-cataplexies essentielles. Revue Neurologique, 116, 471-490.

Gélineau, J. B. E. (1880). De la narcolepsie. Gazette des Hôpitaux de Paris, 53, 626-628.

Guilleminault, C., Wilson, R. A., and Dement, W. C. (1974). A study on cataplexy. Archives of Neurology (Chic.), 31, 255-261.
Lusins, J. O., and Szilagyi, P. A. (1975). Clinical features of chorea associated with systemic lupus erythematosus. American Journal of Medicine, 58, 857-861.

Mackenzie, I. C. K. (1967). Narcolepsy and cataplexy. Practitioner, 198, 520-524.

Nattrass, F. J. (1931). The Commoner Nervous Diseases, p. 137. Oxford University Press, edited by Humphrey Milford.

Parkes, J. D., and Marsden, C. D. (1974). Narcolepsy. British Journal of Hospital Medicine, 12, 325-334.

Penn, A. S., and Rowan, A. J. (1968). Myelopathy in systemic lupus erythematosus. Archives of Neurology (Chic.), 18, 337-349.

Shapiro, W. R. (1975). Treatment of cataplexy with clomipramine. Archives of Neurology (Chic.), 32, 653664.

Wilson, S. A. K. (1928). The narcolepsies. Brain, 51, 63-109.

Yoss, R. E., and Daly, D. D. (1957). Criteria for the diagnosis of the narcoleptic syndrome. Proceedings of the Mayo Clinic, 32, 320-328.

Zarcone, V. (1973). Narcolepsy. New England Jourral of Medicine, 288, 1156-1166. 